\title{
Formulações simples e mista de inoculantes com bactérias diazotróficas, sob diferentes doses de nitrogênio na cultura do arroz irrigado
}

\section{Single mixed formulations of inoculants with diazotrophic bacteria, under different nitrogen rates on the paddy rice crop}

\author{
Paula Bianchet ${ }^{1 *}$; Luis Sangoi ${ }^{2}$; Osmar Klauberg Filho²; David José Miquelluti²; \\ Mariana Alves Ferreira ${ }^{3}$; Jefferson Vieira ${ }^{3}$
}

Resumo

A utilização de bactérias diazotróficas como insumo biológico para a produção de arroz irrigado pode reduzir as aplicações de fertilizantes nitrogenados e contribuir para o desenvolvimento da planta. O uso de formulações mistas de inoculantes pode aumentar a eficiência do processo de fixação biológica de nitrogênio. $\mathrm{O}$ objetivo do trabalho foi avaliar o efeito de formulações simples e mista de inoculantes a base de bactérias diazotróficas sobre o desenvolvimento inicial da cultura do arroz irrigado sob diferentes níveis de N. O experimento foi implantado em casa de vegetação. Os tratamentos foram constituídos por quatro tipos de inoculação (sem inoculação, inoculação com o isolado UDESC AI 27, inoculação com o isolado UDESC FE 22 e inoculação com uma formulação mista dos isolados UDESC AI 27 e UDESC FE 22); e duas doses de nitrogênio mineral (30 e $60 \mathrm{mg} \mathrm{kg}^{-1} \mathrm{de} \mathrm{N}$ ). A cultivar utilizada foi a Epagri 109, de ciclo tardio (superior a 140 dias) e alto potencial produtivo. Os tratamentos foram arranjados num fatorial $(4 \times 2)$ com cinco repetições. O delineamento experimental foi completamente casualizado. A inoculação com os isolados de bactérias diazotróficas reduziu em $18 \%$ a produção de massa seca da parte aérea e em $26 \%$ da fitomassa radicular das plantas de arroz. As plantas inoculadas também apresentaram menor área e volume radicular. Não houve efeito significativo dos tratramentos de inoculação e adubação nitrogenada sobre o número de folhas totais e de perfilhos produzidos por planta, nem sobre o nirogênio acumulado na parte aérea. Os resultados obtidos demonstraram que os isolados utilizados no trabalho não foram efetivos para estimular o crescimento de parte aérea e raiz da cultivar Epagri 109, independentemente do tipo de formulação e da dose de N.

Palavras-chave: Oryza sativa, fixação biológica de nitrogênio, auxina

\begin{abstract}
The use of diazotrophic bacteria as a biological input for the production of paddy rice can reduce nitrogen fertilizer applications and contribute to plant development. The use of mixed inoculants' formulations can increase the efficiency of nitrogen fixation biological process. The objective of this study was to evaluate the effect of single and mixed formulations of inoculants with diazotrophic bacteria on the initial growth of paddy rice plants under different levels of $\mathrm{N}$. The experiment was set in a greenhouse.
\end{abstract}

\footnotetext{
${ }^{1}$ Discente de Doutorado do Programa de Pós-Graduação em Ciências Agrárias CAV, Universidade do Estado de Santa Catarina, UDESC, Av. Luiz de Camões, 2090, 88.520-000, Lages, SC. E-mail: paula_bianchet@yahoo.com.br

2 Profs. do Programa de Pós-Graduação em Ciências Agrárias da UDESC, Lages, SC. E-mail: a21s@cav.udesc.br; a2okf@cav. udesc.br; a2djm@cav.udesc.br

${ }^{3}$ Discentes de Graduação do Curso de Agronomia da UDESC, Bolsistas de iniciação científica da UDESC, Lages, SC. E-mail: maryhferreira@gmail.com; jefferson.vieira05@hotmail.com

* Autor para correspondência
} 
Treatments consisted of four types of inoculation (no inoculation, inoculation with the isolated AI UDESC 27, inoculation with the isolated FE UDESC 22, and inoculation with the mixed formulation of isolated AI UDESC UDESC 27 and FE UDESC 22); and two levels of mineral nitrogen (30 and $60 \mathrm{mg} \mathrm{kg}^{-1}$ of N). The cultivar used was Epagri 109, which presents late maturity (over 140 days) and high yield potential. Treatments were arranged in a factorial design $(4 \times 2)$ with five replicates. The experimental design was completely randomized. Inoculation with diazotrophic bacteria reduced by $18 \%$ and $26 \%$ shoot and root dry matter of rice plants, respectively. Plants also presented lower root area and volume when they were inoculated. There was no significant effect of inoculation and nitrogen rates on the number of leaves and tillers produced per plant or shoot nitrogen accumulation. The results showed that the isolated used in this work were not effective to stimulate shoot and root growth of $\mathrm{cv}$ Epagri 109, regardless of formulation type and rate of $\mathrm{N}$.

Key words: Oryza sativa, biological nitrogen fixation, auxin

\section{Introdução}

As bactérias endofíticas são assim denominadas por colonizarem o interior dos tecidos vegetais e não causarem danos aparentes (DOBBELAERE; VANDERLEYDEN; OKON, 2003). Muitas bactérias endofiticas são diazotróficas, pois são capazes de fixar $\mathrm{N}_{2}$ atmosférico. Algumas plantas podem formar associações com estas bactérias e obter $\mathrm{N}$ por meio da fixação biológica. Diversas bactérias têm sido isoladas da rizosfera do arroz irrigado. Entre elas destacam-se os gêneros Azospirillum, Bacillus, Paenibacillus, Herbaspirillum, Burkholderia e Pseudomonas (KENNEDY; CHOUDHURY; KECSKÉS, 2004).

As bactérias diazotróficas podem contribuir para o desenvolvimento das plantas de diversas formas, tais como o fornecimento de $\mathrm{N}$ por meio da fixação biológica de nitrogênio $(\mathrm{N})$ e a produção de fitormônios, principalmente auxinas, que estimulam o crescimento das plantas (RODRIGUES, 2004).

Muitas bactérias podem ser isoladas de raízes de arroz, mas nem todas apresentam potencial fixador de $\mathrm{N}$ ou produtor de auxinas (CARDOSO, 2008). O genótipo da planta é fundamental no estabelecimento desta associação. A especificidade de hospedeiros é verificada para diferentes espécies de plantas estudas (COELHO et al., 2007) e pode ter resultados diferentes dentro da mesma espécie para cultivares distintas (SABINO, 2007). Kuss et al. (2007), estudando a ocorrência de bactérias endofiticas em nove cultivares de arroz, verificaram afinidade de isolados por algumas cultivares. Nehl, Allem e Brown (1996) consideram que a qualidade dos exsudados radiculares determina a preferência das bactérias por determinadas espécies e cultivares.

O uso de formulações mistas de inoculantes é comum e pode aumentar a eficiência do processo de fixação biológica de nitrogênio (CAMPOS et al., 2003). A Embrapa Agrobiologia desenvolveu recentemente um inoculante para aplicação na cultura da cana-de-açúcar, contendo as bactérias diazotróficas Gluconacetobacter diazotrophicus, Herbaspirillum seropedicae, Herbaspirillum rubrisubalbicans, Azospirillum amazonense e Burkholderia tropica (REIS; PEREIRA; HIPÓLITO, 2009). Cada isolado de bactéria apresenta uma característica distinta de produção de fitormônios, fixação de $\mathrm{N}$ e solubilização de fosfatos. Estas características em associação podem aumentar a resposta da planta à inoculação (PERRIG et al., 2007).

O objetivo deste trabalho foi avaliar o efeito de formulações simples e mista de inoculantes a base de bactérias diazotróficas e doses de nitrogênio na cultura do arroz irrigado.

\section{Material e Métodos}

O experimento foi conduzido em casa de vegetação, no município de Lages/SC, no ano de 2009. As unidades experimentais foram constituídas por baldes plásticos contendo $4 \mathrm{~kg}$ de solo seco 
e peneirado e quatro plantas por balde. O solo utilizado foi classificado como CAMBISSOLO HÁPLICO Tb Distrófico (EMBRAPA, 2006) e apresentava as seguintes características químicas e granulométricas: $\mathrm{pH} \mathrm{H}_{2} \mathrm{O}=4,8$; índice $\mathrm{SMP}=5,0$; $\mathrm{P}=12,5 \mathrm{mg} \mathrm{dm}^{-3} ; \mathrm{K}=105 \mathrm{mg} \mathrm{dm}{ }^{-3} ; \mathrm{Ca}=6,38 \mathrm{cmol}_{c}$ $\mathrm{dm}^{-3} ; \mathrm{Mg}=1,67 \mathrm{cmol}_{\mathrm{c}} \mathrm{dm}^{-3}$, matéria orgânica 27 $\mathrm{g} \mathrm{kg}^{-1}$ e argila $=280 \mathrm{~g} \mathrm{~kg}^{-1}$, areia $=250 \mathrm{~g} \mathrm{~kg}^{-1}$ e silte $=$ $470 \mathrm{~g} \mathrm{~kg}^{-1}$.

O delineamento experimental utilizado foi inteiramente casualizado com cinco repetições, num esquema fatorial $4 \times 2$, constituído por quatro formulações com inoculantes com bactérias diazotróficas (sem inoculação, inoculação com o isolado UDESC AI 27, inoculação com o isolado UDESC FE 22 e uma formulação mista composta pelos isolados UDESC AI 27 e UDESC FE 22) e duas doses de $\mathrm{N}$ mineral $\left(30\right.$ e $60 \mathrm{mg} \mathrm{kg}^{-1} \mathrm{~N}$, correspondentes a 60 e $120 \mathrm{~kg}$ de $\mathrm{N} \mathrm{ha}^{-1}$, que representam metade da dose e a dose recomendada para a cultura na região do Alto Vale do Itajaí, SC). Cada unidade experimental foi constituída por baldes plásticos contendo $4 \mathrm{~kg}$ de solo seco e peneirado e quarto plantas por bande. A cultivar utilizada foi a cultivar Epagri 109, do grupo moderno, de ciclo tardio (superior a 140 dias) e alto potencial produtivo, uma das mais cultivadas em Santa Catarina

O solo foi inundado 30 dias antes da semeadura e permaneceu com uma lâmina de água de aproximadamente $5 \mathrm{~cm}$ de profundidade durante todo o período experimental para simular a condição de campo das lavouras catarinenses de arroz irrigado, onde os quadros são inundados durante o preparo do solo para estabilização das reações de redução antes da semeadura. A adubação foi definida segundo análise de solo e recomendação da Sosbai (2010). Foram aplicadas quantidades equivalentes a $50 \mathrm{~kg}$ $\mathrm{P}_{2} \mathrm{O}_{5} \mathrm{ha}^{-1} \mathrm{e} 50 \mathrm{~kg} \mathrm{~K}_{2} \mathrm{O} \mathrm{ha}{ }^{-1}$, as quais foram corrigidas para $4 \mathrm{~kg}$ de solo em cada unidade experimental. $\mathrm{O}$ fósforo e o potássio foram incorporados ao solo dois dias antes da semeadura. A adubação nitrogenada foi realizada em duas aplicações de cobertura quando as plantas estavam no estádio V4 (colar formado na quarta folha do colmo principal) e V8 (colar formado na oitava folha do colmo principal), conforme escala proposta por Counce, Keisling e Mitchell (2000). Em cada estádio aplicou-se 15 e 30 $\mathrm{mg} \mathrm{kg}^{-1}$ de $\mathrm{N}$ (correspondentes à metade da dose por tratamento), via líquida.

As sementes foram desinfetadas através da imersão em álcool por 5 minutos e após em hipoclorito de sódio por 30 segundos. Em seguida elas foram lavadas com água destilada. A prégerminação foi realizada seguindo metodologia descrita por Epagri (2002). Após a pré-germinação, as sementes foram imersas em inoculante líquido por três horas. Para o preparo do inoculante colônias purificadas foram multiplicadas em meio de cultura DYGS (DÖBEREINER; BALDANI; BALDANI, 1995) por 24h sob agitação constante e temperatura de $28^{\circ} \mathrm{C}$. A concentração do inoculante era de $10^{8}$ células $\mathrm{mL}^{-1}$ no momento da inoculação. A semeadura foi realizada no dia 28 de novembro de 2009.

A colheita foi realizada no dia 28 de janeiro de 2010 quando as plantas se encontravam no estádio V10(colar formado na $10^{\circ}$ folha do colmo principal e iniciação da panícula), da escala de Counce, Keisling e Mitchell (2000). A época de colheita do ensaio foi definida levando em consideração o volume de solo disponível em cada unidade experimental (4 kg) para que não houvesse restrição ao crescimento de raízes e parte aérea da cultura. No dia da colheita foram realizadas avaliações morfológicas de parte aérea, utilizando-se as quatro plantas contidas em cada repetição. Determinaramse a estatura de plantas, medindo-se a distância da base do colmo até a ponta da última folha totalmente expandida, o número de perfilhos e o número de folhas produzidas por planta. Quando concluídas as avaliações morfológicas foi realizada a determinação do índice relativo de clorofila, com clorofilômetro portátil, marca Clorofilog 1030 Falker, realizando a leitura na última folha completamente expandida das plantas de arroz. 
As quatro plantas foram cortadas, separando-se raiz e parte aérea. As raízes foram lavadas, deixadas dois minutos em papel toalha, e pesadas, obtendose o peso úmido. Após foi retirada uma amostra de $10 \mathrm{~g}$ para a série de diluições. Estas amostras foram desinfetadas pela imersão em solução de hipoclorito de sódio (1\%) por 30 segundos, enxaguadas com água destilada e trituradas em $90 \mathrm{~mL}$ de solução de sacarose (4\%) com o auxílio de um misturador. Em seqüência procedeu-se as diluições seriadas até obter $10^{-7}$, para a determinação do crescimento de rizobactérias nos meios NFb e LGI. A contagem das bactérias foi realizada utilizando o método do número mais provável de microorganismos (NMP), consultando a tabela de Mc Crady (DÖBEREINER; BALDANI; BALDANI, 1995), para três repetições por diluição. Considerou-se crescimento positivo a formação de uma película aetotáxica típica próximo da superfície do meio após sete dias de incubação a $32^{\circ} \mathrm{C}$.

Os parâmetros morfológicos da raiz foram determinados conforme metodologia apresentada por Schenk e Barber (1979). O comprimento (L) de raiz foi determinado pelo método de intersecção descrito por Tennant (1975). O raio médio (R) da raiz foi calculado pela fórmula $\mathrm{R}=\left(\mathrm{P}_{\mathrm{f}} / \mathrm{L} \pi\right)^{1 / 2}$, onde $\mathrm{P}_{\mathrm{f}}$ é o peso fresco da raiz. Essa fórmula pressupõe a forma cilíndrica das raízes com densidade de 1,0g $\mathrm{cm}^{-3}$. A área e o volume das raízes foram calculadas segundo Rossiello (1995) pelas fórmulas $A=(2 \pi$ $R L)$ e $V=\left(\pi R^{2}\right) L$.

As partes das plantas foram secas em estufa a $60^{\circ} \mathrm{C}$ até atingirem peso constante para determinação da massa seca de parte aérea e de raiz. Após, as amostras foram moídas para a determinação da percentagem de $\mathrm{N}$ no tecido, conforme metodologia descrita por Tedesco et al. (1995).

Os dados obtidos foram submetidos à análise de variância pelo teste F. Quando alcançada a significância estatística, foram avaliados contrastes de médias para as inoculações e o teste DMS para as doses de N, a $5 \%$ de probabilidade. Testaram-se três contrastes: $\mathrm{C} 1=\mathrm{S} / \mathrm{I}-\mathrm{AI} 27$ - FE 22 -(AI 27+FE22); $\mathrm{C} 2=(\mathrm{AI} 27+\mathrm{FE} 22)-\mathrm{AI} 27-\mathrm{FE} \mathrm{22}$ C $3=$ AI $27-$ FE 22. O primeiro contraste avaliou as diferenças entre parcelas não inoculadas e inoculadas; o segundo as diferenças entre a formulação mista e as formulações simples; e o terceiro a diferença entre os dois isolados.

\section{Resultados e Discussão}

Não houve efeito das doses de $\mathrm{N}$ na produção de fitomassa da cultura, para o número de folhas totais e núnero de perfilhos (Tabela 1). A colheita das plantas foi realizada antes do final do período de desenvolvimento vegetativo, quando as mesmas se encontravam no estádio V10 da escala de Counce, Keisling e Mitchell (2000). Assim, no momento da colheita, as plantas não haviam atingido a máxima produção de fitomassa e a maior demanda por nitrogênio, que segundo a Sosbai (2010) está concentrada entre os estádios R1 diferenciação da panícula) e R5 (elongação do grão) da escala proposta por Counce, Keisling e Mitchell (2000).

Também não houve efeito significativo da interação entre a adubação nitrogenada e a inoculação sobre as variáveis de fitomassa (Tabela 1). As massas secas de parte aérea e das raízes foram influenciadas pelo efeito principal da inoculação. As plantas dos tratamentos que receberam inoculação com os isolados de bactérias diazotróficas produziram $18 \%$ menos de massa seca da parte aérea e $26 \%$ da fitomassa radicular das plantas de arroz em relação as plantas que recebaram adubação com $\mathrm{N}$ mineral (Tabela 2). 
Tabela 1. Quadrados médios, valores de F e probabilidades para as diferentes variáveis analisadas.

\begin{tabular}{lccccccccc}
\hline Variáveis & \multicolumn{3}{c}{ Inoculante } & \multicolumn{3}{c}{ Dose } & \multicolumn{3}{c}{ Inoc x Dose } \\
\hline Massa Seca PA & QM & F & Prob & QM & F & Prob & QM & F & Prob \\
Massa Seca Raiz & 1,956 & 3,712 & 0,021 & 0,363 & 1,409 & 0,244 & 0,201 & 0,780 & 0,513 \\
N acumulado PA & 37,316 & 0,539 & 0,001 & 0,0007 & 0,004 & 0,953 & 0,078 & 0,378 & 0,768 \\
N acumulado Raiz & 109,43 & 3,461 & 0,570 & 31,506 & 0,319 & 0,576 & 158,89 & 1,607 & 0,207 \\
Folhas Totais & 0,0683 & 1,6318 & 0,201 & 11,428 & 0,361 & 0,552 & 8,880 & 0,281 & 0,839 \\
Perfilhos & 0,014 & 0,877 & 0,463 & 0,005 & 0,955 & 0,759 & 0,061 & 1,449 & 0,247 \\
Estatura & 43,843 & 4,870 & 0,0067 & 3,136 & 0,348 & 0,559 & 8,440 & 0,938 & 0,434 \\
Clorofila & 17,33 & 3,6424 & 0,023 & 74,53 & 15,66 & 0,0004 & 3,062 & 0,643 & 0,593 \\
Área radicular & 1,333 & 4,004 & 0,016 & 1,561 & 0,047 & 0,830 & 1,265 & 0,380 & 0,768 \\
Volume radicular & 5,672 & 5,073 & 0,005 & 1086032 & 0,097 & 0,757 & 1,712 & 1,531 & 0,225 \\
Raio radicular & 0,006 & 3,382 & 0,030 & 2.500 & 0,001 & 0,971 & 0,0018 & 0,979 & 0,415 \\
NMP NFb & 36,91 & 6,17 & 0,002 & 10,01 & 1,67 & 0,205 & 12,18 & 2,036 & 0,129 \\
NMP LGI & 4,908 & 1,882 & 0,153 & 3,147 & 1,207 & 0,28 & 5,123 & 1,965 & 0,139 \\
\hline
\end{tabular}

Fonte: Elaboração dos autores.

Tabela 2. Massa seca de parte aérea e radicular da cultivar de arroz Epagri 109 submetida a inoculações com diferentes formulações de bactérias promotoras de crescimento vegetal, na média de duas doses de $\mathrm{N}$ e seus contrastes de médias. Lages, SC, 2010.

\begin{tabular}{|c|c|c|c|c|}
\hline Inoculações & $\frac{\text { Parte aérea }}{\left(\mathrm{g} \mathrm{pl}^{-1}\right)}$ & $\mathbf{C 1}^{1 /}$ & $\mathrm{C} 2$ & C3 \\
\hline Sem Inoculação & 3,44 & 3 & 0 & 0 \\
\hline UDESC AI 27 & 2,78 & -1 & -1 & 1 \\
\hline UDESC FE 22 & 2,93 & -1 & -1 & -1 \\
\hline AI $27+$ FE 22 & 2,8 & -1 & 2 & 0 \\
\hline Probabilidade & & $0,002 *$ & $0,769 \mathrm{~ns}$ & $0,491 \mathrm{~ns}$ \\
\hline Inoculações & $\frac{\text { Raízes }}{\left(\mathrm{g} \mathrm{pl}^{-1}\right)}$ & $\mathrm{C} 1$ & $\mathrm{C} 2$ & $\mathrm{C3}$ \\
\hline Sem Inoculação & 2,53 & 3 & 0 & 0 \\
\hline UDESC AI 27 & 1,76 & -1 & -1 & 1 \\
\hline UDESC FE 22 & 2,1 & -1 & -1 & -1 \\
\hline AI $27+$ FE 22 & 1,75 & -1 & 2 & 0 \\
\hline Probabilidade & & $0,0003^{*}$ & $0,320 \mathrm{~ns}$ & $0,100 \mathrm{~ns}$ \\
\hline
\end{tabular}

${ }^{1 /} \mathrm{C} 1=$ sem inoculação $\mathrm{x}$ inoculado; $\mathrm{C} 2=$ formulação mista $\mathrm{x}$ simples $\mathrm{C} 3=$ isolado AI $27 \mathrm{x}$ isolado FE 22.

*Significativo a $5 \%$.

ns Não significativo.

Fonte: Elaboração dos autores.

Este resultado contraria os reportados Didonet, Martin-Didonet e Gomes (2003) e Sabino (2007) que constataram efeito benéfico da inoculação de bactérias diazotróficas sobre o crescimento de plantas de arroz de sequeiro, em ensaios conduzidos a campo. A sensibilidade de genótipos de arroz a altas concentrações de fitormônios pode explicar os efeitos negativos da inoculação sobre a produção de massa seca nas plantas no presente trabalho. Segundo Lambrecht et al. (2000), quando são produzidas altas quantidades de auxinas exógenas, pode ocorrer inibição do desenvolvimento das raízes. 
O isolado AI 27 foi analisado in vitro e a sua produção de auxinas foi de $120 \mu \mathrm{g} \mathrm{mL}^{-1}$. Esta é a maior produção auxínica para os isolados encontrados no estudo de ocorrência em lavouras de arroz irrigado no Estado de Santa Catarina (CARDOSO, 2008). O isolado FE 22 foi encontrado em lavouras de feijão e apresentou uma produção de auxinas de $30 \mu \mathrm{g} \mathrm{mL} \mathrm{m}^{-1}$. Estes valores indicam uma alta capacidade de produção de auxinas que poderiam estimular o crescimento do arroz. Contudo, a resposta das plantas às auxinas liberadas pelas bactérias pode variar do efeito benéfico ao inibitório, dependendo da concentração (ARAÚJO, 2008). Estudos conduzidos por Bacilio-Jiménez et al. (2001), testando a inoculação de Azospirillum brasiliense em plântulas de arroz, verificaram uma redução do crescimento das plântulas inoculadas, em relação às não inoculadas.

Segundo Kuss et al. (2007) e Sabino (2007), além da sensibilidade do genótipo de arroz a concentrações de auxinas exógenas, outro fator que influencia no resultado das inoculações de bactérias em plantas é a interação planta-bactéria. O mesmo isolado inoculado em diferentes genótipos de arroz responde de forma distinta. No estudo realizado por Bacilio-Jimenez et al. (2001) foi verificado que dois isolados de Azopirillum brasiliense apresentaram comportamento distintos para as duas cultivares inoculadas, sendo o isolado A 9-81 mais inibidor para a cultivar Morelos e o isolado UAP- 154 mais inibidor para a cultivar Apatzingán. Nehl, Allem e Brown
(1996) reportaram que a qualidade dos exsudados radiculares determina a preferência das bactérias por algumas espécies e cultivares distintas. A produção de fitomassa da cultivar Epagri 109 não respondeu positivamente a inoculação com formulações simples e mista de bactérias diazotróficas. É possível que os exudatos radiculares por ela liberados não sejam favoráveis ao desenvolvimento dos isolados utilizados no trabalho.

Não houve efeito signicativo para o acumulo de nitrogênio na parte aérea em função de doses de $\mathrm{Ne}$ inoculações (Tabela 3). Por outro lado, houve efeito significativo da inoculação para acumulo de $\mathrm{N}$ raízes. O $\mathrm{N}$ acumulado nas raízes foi $21 \%$ superior quando as plantas não foram inoculadas. A menor quantidade de massa seca de raiz nos tratamentos com inoculação (Tabela 2) pode ser responsável pela menor absorção de $\mathrm{N}$ pelas raízes (Tabela 3 ). Mesmo com a inoculação do isolado FE 22, que apresentou alta produção de $\mathrm{N}$ in vitro em trabalho realizado por Neves (2009), não houve acréscimo no acúmulo de $\mathrm{N}$ da parte aérea e radicular. Este resultado pode ter sido influenciado pela interação planta-bactéria que não propiciou ao isolado condições para expressar na planta seu potencial de fixação de N no arroz irrigado. Genótipos de arroz recebem diferentes contribuições da fixação de $\mathrm{N}$ pelas bactérias, sendo alguns mais eficientes que outros (CAMPOS et al., 2003). Esta característica enfatiza a importância da interação planta-bactéria no sucesso da associação. 
Tabela 3. Nitrogênio acumulado na parte aérea e radicular da cultivar de arroz Epagri 109 submetida a inoculações com diferentes formulações de bactérias promotoras de crescimento vegetal, na média de duas doses de N. Lages, SC, 2010.

\begin{tabular}{|c|c|c|c|c|}
\hline Inoculações & $\begin{array}{l}\text { Parte aérea } \\
\left(\mathrm{mg} \mathrm{pl}^{-1}\right)\end{array}$ & $\mathrm{C1}^{1 /}$ & $\mathrm{C2}$ & $\mathbf{C 3}$ \\
\hline Sem Inoculação & 50,8 & 3 & 0 & 0 \\
\hline UDESC AI 27 & 48,8 & -1 & -1 & 1 \\
\hline UDESC FE 22 & 47,5 & -1 & -1 & -1 \\
\hline AI $27+$ FE 22 & 53,4 & -1 & 2 & 0 \\
\hline Probabilidade & $0,207 \mathrm{~ns}$ & & & \\
\hline Inoculações & $\begin{array}{c}\text { Raízes } \\
\left(\mathrm{mg} \mathrm{pl}^{-1}\right)\end{array}$ & C1 & $\mathrm{C} 2$ & $\mathrm{C3}$ \\
\hline Sem Inoculação & 23,6 & 3 & 0 & 0 \\
\hline UDESC AI 27 & 18,0 & -1 & -1 & 1 \\
\hline UDESC FE 22 & 21,8 & -1 & -1 & -1 \\
\hline AI $27+$ FE 22 & 16,4 & -1 & 2 & 0 \\
\hline Probabilidade & & $0,025^{*}$ & $0,118 \mathrm{~ns}$ & $0,144 \mathrm{~ns}$ \\
\hline
\end{tabular}

${ }^{1} \mathrm{C} 1=$ sem inoculação $\mathrm{x}$ inoculado; $\mathrm{C} 2=$ formulação mista $\mathrm{x}$ simples $\mathrm{C} 3=$ isolado AI $27 \mathrm{x}$ isolado FE 22.

*Significativo a $5 \%$.

ns Não significativo.

Fonte: Elaboração dos autores.

Não houve efeito significativo dos tratamentos de inoculação e adubação nitrogenada sobre o número de folhas totais e de perfilhos (Tabela 4). Um dos fatores que influenciam na emissão de perfilhos é a absorção de N (LARROSA et al., 2001). Como não ocorreram diferenças no acúmulo de $\mathrm{N}$ na parte aérea (Tabela 3), a emissão de perfilhos também não foi afetada. Provavelmente a colheita efetuada antes do final do período de perfilhamento favoreceu a ausência de efeito significativo dos tratamentos sobre o número de perfilhos produzidos.

Tabela 4. Número de folhas totais e perfilhos da cultivar de arroz Epagri 109 submetida a inoculações com diferentes formulações de bactérias promotoras de crescimento vegetal, na média de duas doses de N. Lages, SC, 2010.

\begin{tabular}{ccc}
\hline Inoculações & Folhas totais $\left(\mathrm{n}^{\circ}\right)$ & Perfilhos $\left(\mathrm{n}^{\circ}\right)$ \\
\hline Sem Inoculação & $24,0 \mathrm{~ns}$ & $4,7 \mathrm{~ns}$ \\
UDESC AI 27 & 25,2 & 4,6 \\
UDESC FE 22 & 23,9 & 4,4 \\
AI 27 + FE 22 & 23,0 & 4,3 \\
\hline Probabilidade & $0,247 \mathrm{~ns}$ & $0,841 \mathrm{~ns}$ \\
\hline
\end{tabular}

ns Não significativo a $5 \%$.

Fonte: Elaboração dos autores.

A estatura de plantas foi afetada pelo efeito da inoculação. Verificou-se que as plantas foram $7 \%$ mais altas quando inoculadas com o isolado FE 22 do que com o AI 27 (Tabela 5). Os demais contrastes não foram significativos. Araújo (2008) não encontrou diferença na estatura de plantas de diversos genótipos de arroz inoculadas com oito isolados de bactérias diazotróficas. Entretanto, Kuss 
(2006), avaliando cinco isolados e um controle, verificou aumento na estatura de plantas de arroz de três cultivares do IRGA quando as plantas foram cultivadas em solução nutritiva. Já quando as plantas foram cultivadas em solo houve diferença significativa apenas para uma cultivar, sendo que um isolado promoveu aumento na estatura de planta.

O índice relativo de clorofila também foi influenciado pelo efeito simples da inoculação. A inoculação com a formulação mista propiciou maior índice relativo de clorofila do que a inoculação com as formulações simples (Tabela 5). O índice relativo de clorofila se correlaciona positivamente com o teor de clorofila e com o teor de $\mathrm{N}$ dos tecidos. Isto sugere que o teor de $\mathrm{N}$ na última folha completamente expandida foi maior quando utilizou-se a formulação mista na inoculação do arroz. Quando o indice é avaliado na folha bandeira do arroz, ele se correlaciona diretamente com o rendimento de grãos (TURNER; JUND, 1991).

Tabela 5. Estatura e índice relativo de clorofila da cultivar de arroz Epagri 109 submetida a inoculações com diferentes formulações de bactérias promotoras de crescimento vegetal, na média de duas doses de $\mathrm{N}$ e seus contrastes de médias. Lages, SC, 2010.

\begin{tabular}{|c|c|c|c|c|}
\hline Inoculações & $\begin{array}{c}\text { Estatura } \\
(\mathrm{cm})\end{array}$ & $\mathbf{C 1}^{1 /}$ & $\mathrm{C} 2$ & C3 \\
\hline Sem Inoculação & 59,4 & 3 & 0 & 0 \\
\hline UDESC AI 27 & 58,8 & -1 & -1 & 1 \\
\hline UDESC FE 22 & 63,4 & -1 & -1 & -1 \\
\hline AI $27+$ FE 22 & 59,9 & -1 & 2 & 0 \\
\hline Probabilidade & & $0,226 \mathrm{~ns}$ & $0,307 \mathrm{~ns}$ & $0,002 *$ \\
\hline Inoculações & $\begin{array}{c}\text { Índice relativo de } \\
\text { clorofila }\end{array}$ & $\mathrm{C} 1$ & $\mathrm{C} 2$ & $\mathrm{C} 3$ \\
\hline Sem Inoculação & 33,1 & 3 & 0 & 0 \\
\hline UDESC AI 27 & 34,1 & -1 & -1 & 1 \\
\hline UDESC FE 22 & 33,4 & -1 & -1 & -1 \\
\hline AI $27+$ FE 22 & 36,0 & -1 & 2 & 0 \\
\hline Probabilidade & & $0,08 \mathrm{~ns}$ & $0,01 *$ & $0,47 \mathrm{~ns}$ \\
\hline
\end{tabular}

${ }^{1 /} \mathrm{C} 1=$ sem inoculação $\mathrm{x}$ inoculado; $\mathrm{C} 2=$ formulação mista $\mathrm{x}$ simples $\mathrm{C} 3=$ isolado AI $27 \mathrm{x}$ isolado FE 22.

*Significativo a $5 \%$.

ns Não significativo.

Fonte: Elaboração dos autores.

A área e o volume radicular foram influenciados pelo efeito principal da inoculação. (Tabela 6). Estes parâmetros radiculares reduziram $21 \%$ e $23 \%$, respectivamente, com a inoculação de bactérias diazotróficas, em relação ao tratamento não inoculado.
As menores área e volume de raízes contribuíram para reduzir a fitomassa radicular nos tratamentos inoculados (Tabela 2). Já o raio médio radicular foi maior com a utilização da formulação mista AI 27+ FE 22 do que com as formulações simples. 
Tabela 6. Área, volume e raio médio radicular da cultivar de arroz Epagri 109, submetida a inoculações com diferentes formulações de bactérias promotoras de crescimento vegetal, na média de duas doses de $\mathrm{N}$ e seus contrastes de médias. Lages, SC, 2010.

\begin{tabular}{|c|c|c|c|c|}
\hline Inoculações & $\frac{\text { Área }}{\left(\mathrm{cm}^{2} \mathrm{pl}^{-1}\right)}$ & $\mathbf{C 1}^{1 /}$ & $\mathrm{C} 2$ & C3 \\
\hline Sem Inoculação & 100 & 3 & 0 & 0 \\
\hline UDESC AI 27 & 82 & -1 & -1 & 1 \\
\hline UDESC FE 22 & 83 & -1 & -1 & -1 \\
\hline AI $27+$ FE 22 & 71 & -1 & 2 & 0 \\
\hline Probabilidade & & $0,004^{*}$ & $0,115 \mathrm{~ns}$ & $0,852 \mathrm{~ns}$ \\
\hline Inoculações & $\begin{array}{l}\text { Volume } \\
\left(\mathrm{cm}^{3} \mathrm{pl}^{-1}\right)\end{array}$ & $\mathrm{C} 1$ & $\mathrm{C} 2$ & $\mathrm{C} 3$ \\
\hline Sem Inoculação & 20 & 3 & 0 & 0 \\
\hline UDESC AI 27 & 15 & -1 & -1 & 1 \\
\hline UDESC FE 22 & 16 & -1 & -1 & -1 \\
\hline AI $27+$ FE 22 & 15 & -1 & 2 & 0 \\
\hline Probabilidade & & $0,001 *$ & $0,682 \mathrm{~ns}$ & $0,400 \mathrm{~ns}$ \\
\hline Inoculações & $\begin{array}{c}\text { Raio médio } \\
(\mathrm{mm})\end{array}$ & $\mathrm{C1}$ & $\mathrm{C} 2$ & C3 \\
\hline Sem Inoculação & 0,41 & 3 & 0 & 0 \\
\hline UDESC AI 27 & 0,37 & -1 & -1 & 1 \\
\hline UDESC FE 22 & 0,39 & -1 & -1 & -1 \\
\hline AI $27+$ FE 22 & 0,43 & -1 & 2 & 0 \\
\hline Probabilidade & & $0,493 \mathrm{~ns}$ & $0,008^{*}$ & $0,223 \mathrm{~ns}$ \\
\hline
\end{tabular}

${ }^{1 /} \mathrm{C} 1=$ sem inoculação $\mathrm{x}$ inoculado; $\mathrm{C} 2=$ formulação mista $\mathrm{x}$ simples $\mathrm{C} 3=$ isolado AI $27 \mathrm{x}$ isolado FE 22.

*Significativo a $5 \%$.

ns Não significativo.

Fonte: Elaboração dos autores.

Estes resultados possivelmente podem ser explicados pela sensibilidade das raízes à alta concentração de auxinas, que pode causar efeito oposto ao desejado, pois o hormônio liberado em altas quantidades pode provocar efeitos negativos de crescimento das plantas. El-Khawas e Adachi (1999), testando Azospirillum brasiliense e Klebsiella pneunomiae em raízes de arroz, observaram um estímulo no comprimento e área radicular a pequenas concentrações de AIA. Mas com o aumento da concentração de AIA houve redução no comprimento radicular das plantas, sendo menor que no tratamento não inoculado.
A população de bactérias nas raízes das plantas de arroz foi afetada pela inoculação. A presença de bactérias promotoras de crescimento vegetal no tratamento controle foi menor que nos tratamentos com inoculação quando avaliada em meio $\mathrm{NFb}$ (Tabela 7). Isto, corrobora os dados de Perin et al. (2003), que estudando a presença de bactérias diazotróficas em milho e arroz pelo método de imunolocalização, verificaram a ocorrência de bactérias nos tecidos de plantas que não haviam sido inoculados, comprovando o estabelecimento de bactérias nativas do solo nas plantas cultivadas e justificando a presença de bactérias no tratamento controle. 
Tabela 7. Número mais provável de bactérias promotoras de crescimento vegetal $\left(\log _{10}\right)$ obtidas a partir dos meios $\mathrm{NFb}$ e LGI nas raízes da cultivar de arroz Epagri 109 submetida a inoculações com diferentes formulações de bactérias promotoras de crescimento vegetal, na média de duas doses de N e seus contrastes de médias. Lages, SC, 2010.

\begin{tabular}{ccccc}
\hline Inoculações & NFb & $\mathbf{C 1}^{1 /}$ & $\mathbf{C 2}$ & $\mathbf{C 3}$ \\
\hline Sem Inoculação & 1,5 & 3 & 0 & 0 \\
UDESC AI 27 & 3,3 & -1 & -1 & 1 \\
UDESC FE 22 & 4,9 & -1 & -1 & -1 \\
AI 27 + FE 22 & 5,9 & -1 & 2 & 0 \\
\hline Probabilidade & & $0,001^{*}$ & $0,07 \mathrm{~ns}$ & $0,147 \mathrm{~ns}$ \\
\hline Inoculações & LGI & $\mathbf{C 1}$ & $\mathbf{C 2}$ & $\mathbf{C 3}$ \\
\hline Sem Inoculação & 5,2 & 3 & 0 & 0 \\
UDESC AI 27 & 5,3 & -1 & -1 & 1 \\
UDESC FE 22 & 6,4 & -1 & -1 & -1 \\
AI 27 + FE 22 & 6,5 & -1 & 2 & 0 \\
\hline Probabilidade & & $0,11 \mathrm{~ns}$ & $0,44 \mathrm{~ns}$ & $0,33 \mathrm{~ns}$ \\
\hline
\end{tabular}

${ }^{1 /} \mathrm{C} 1=$ sem inoculação $\mathrm{x}$ inoculado; $\mathrm{C} 2=$ formulação mista $\mathrm{x}$ simples $\mathrm{C} 3=$ isolado AI $27 \mathrm{x}$ isolado FE 22.

*Significativo a $5 \%$.

ns Não significativo.

Fonte: Elaboração dos autores.

Nas determinações com o meio LGI, a presença de bactérias foi similar para todos os tratamentos, incluindo o controle sem inoculação (Tabela 7). Isto ocorreu devido a utilização de solo não esterilizado que apresenta bactérias nativas que podem atingir populações semelhantes às observadas nos tratamentos inoculados. Outros autores também encontraram presença similar de bactérias para tratamentos com e sem inoculação de bactérias diazotróficas (SABINO, 2007). Para a avaliação de um inoculante para o cultivo de arroz no sistema prégerminado não é possível proceder a esterilização do solo. As características deste cultivo são dependentes das reações de redução que ocorrem no solo após o alagamento, devido a atividade microbiana no solo. Além disso, a utilização de solo não esterilizado promove um ambiente mais competitivo e semelhante às condições encontradas a campo. Contudo, a presença das bactérias não significa que as plantas estão sendo beneficiadas pela fixação biológica do $\mathrm{N}$ ou pela produção de fitohormônios (BODDEY, 1995).

Apesar da redução de fitomassa com a inoculação encontrada neste experimento, muitos resultados positivos da associação de bactérias diazotróficas em gramineas vem sendo relatados por diversos autores. Neste sentido, Hungria et al. (2010) e Novakowiski et al. (2011) verificaram incremento na produtividade do milho inoculado com Azospirillum brasiliense. Guimarães, Baldani e Baldani (2003) constataram incremento de $111 \%$ na fitomassa de arroz de sequeiro quando inoculado com estirpes de Herbaspirillum.

Os resultados obtidos no trabalho evidenciam a complexidade do sistema alagado para o estudo da contribuição de inoculações com bactérias promotoras de crescimento em arroz irrigado. As alterações químicas, físicas e biológicas promovidas pelo alagamento do solo, influenciam no desenvolvimento das bactérias, reduzindo o seu efeito benéfico sobre o crescimento da cultura.

\section{Conclusão}

A inoculação com formulações simples e mista dos isolados AI 27 e Fe 22 não estimulou a produção de fitomassa da parte aérea e de raízes da cultivar Epagri 109, independentemente da dose de $\mathrm{N}$ avaliada no trabalho. 


\section{Agradecimentos}

\section{A Fundação de Apoio a Pesquisa} Científica e Tecnológica do Estado de Santa Catarina (FAPESC) pela concessão de Bolsa de Estudos à primeira autora do trabalho. Ao Conselho Nacional de Desenvolvimento Científico e Tecnológico (CNPq) pela concessão de Bolsa de Produtividade em Pesquisa ao segundo autor do trabalho.

\section{Referências}

ARAÚJO, A. E. Caracterização e uso de bactérias diazotróficas isoladas de diferentes cultivares de arroz originárias do estado do Maranhão. 2008. Tese (Doutorado em Ciências) - Universidade Federal Rural do Rio de Janeiro, Rio de Janeiro.

BACILIO-JIMÉNEZ， M.; AGUILAR-FLORES， S.; VALLE, S. M. V.; DEL PÉREZ A.; ZEPEDA, A.; ZENTENO E. Endophytic bacteria in rice seeds inhibit early colonization of roots by Azospirillum brasilense. Soil Biology and Biochemistry, Oxford, v. 33, n. 2, p. 167-172, 2001.

BODDEY, R. M. Biological nitrogen fixation in sugarcane: a key to energetically viable biofuel production. Critical Reviews in Plant Sciences, Boca Raton, v. 14, n. 3, p. 263-279, 1995.

CAMPOS, D. V. B.; RESENDE, A. S.; ALVES, B. J. R; BODDEY, R. M.; URQUIAGA, S. Contribuição da fixação biológica de nitrogênio para a cultura de arroz sob inundação. Agronomia (UFRRJ), Seropédica, v. 37, n. 2, p. 41-46, 2003.

CARDOSO, I. C. M. Ocorrência e diversidade de bactérias endofiticas do gênero Azospirillum na cultura do arroz irrigado em Santa Catarina. 2008. Dissertação (Mestrado em Manejo do Solo) - Universidade do Estado de Santa Catarina, Lages.

COELHO, L. F.; FREITAS, S. S.; MELO, A. M. T.; AMBROSANO, G. M. B. Interação de bactérias fluorescentes do gênero Pseudomonas e de Bacillus spp. com a rizosfera de diferentes plantas. Revista Brasileira de Ciência do Solo, Viçosa, MG, v. 31, n. 6, p. 14131420, 2007.

COUNCE, P. A.; KEISLING, T. C.; MITCHELL, A. J. A uniform, objective, and adaptive system for expressing rice development. Crop Science, Madison, v. 40, n. 2, p. 436-443, 2000.

DIDONET, A. D.; MARTIN-DIDONET, C. C. G.; GOMES, G. F. Avaliação de linhagens de arroz de terras altas inoculadas com Azospirillum lipoferum Sp59b e A. brasilense Sp245. Goiânia: Embrapa-CNPAF, 2003. 4 p. (Embrapa-CNPAF, Comunicado técnico, 69).

DOBBELAERE, S.; VANDERLEYDEN, J.; OKON, Y. Plant growth-promoting effects of diazotrophs in the rhizosphere. Critical Reviews in Plant Sciences, Boca Raton, v. 22, n. 2, p. 107-149, 2003.

DÖBEREINER, J.; BALDANI, V. L. D.; BALDANI, J. I. Como isolar e identificar bactérias diazotróficas de plantas não-leguminosas. Itaguaí: EMBRAPA/CNPAB, 1995. 10 p. (EMBRAPA - SPI, Comunicado técnico, 60).

EL-KHAWAS, H.; ADASHI, K. Identification and quantification of auxins in culture media of Azospirillum and klebsiella and their effect on rice roots. Biology and Fertility of Soils, Berlim, v. 28, n. 4, p. 377-381, 1999.

EMPRESA BRASILEIRA DE PESQUISA AGROPECUÁRIA - EMBRAPA. Sistema brasileiro de classificação de solos. 2. ed. Brasília: Embrapa, 2006. $306 \mathrm{p}$.

EMPRESA CATARINENSE DE PESQUISA AGROPECUÁRIA E EXTENSÃO RURAL DE SANTA CATARINA - EPAGRI. A cultura do arroz irrigado prégerminado. Florianópolis: Epagri, 2002. 273 p.

GUIMARÃES, S. L.; BALDANI, J. I.; BALDANI, V. L. D. Efeito da inoculação de bactérias diazotróficas endofíticas em arroz de sequeiro. Agronomia (UFRRJ), Seropédica, v. 37, n. 2, p. 25-30, 2003.

HUNGRIA, M.; CAMPOS, R. J.; SOUZA, E. M. S.; PEDROSA, F. O. Inoculation with selected strains of Azospirillum brasiliense and A. Lipoferum improves yields of maize and wheat in Brazil. Plant and Soil, Netherlands, v. 31, n. 1-2, p. 413-425, 2010.

KENNEDY, I. R.; CHOUDHURY, A. T. M. A.; KECSKÉS, M. L. Non-symbiotic bacterial diazotrophs in crop-farming systems: can their potential for plant growth promotion be better exploited? Soil Biology and Biochemistry, London, v. 36, n. 8, p. 1229-1244, 2004.

KUSS, A. V. Fixação de nitrogênio por bactérias diazotróficas em cultivares de arroz irrigado. 2006. Tese (Doutorado em Ciência do Solo) - Universidade Federal de Santa Maria, Santa Maria.

KUSS, A. V.; KUSS, V. V.; LOVATO, T.; FLÔRES, M. L. Fixação de nitrogênio e produção de ácido indolacético in vitro por bactérias diazotróficas endofíticas. Pesquisa Agropecuária Brasileira, Brasília, v. 42, n. 10, p. 14591465, 2007.

LAMBRECHT, M.; OKON, Y.; BROEK, A. V.; VANDERLEYDEN, J. Indol-3-acetic acid: a reciprocal signaling molecule in bacteria-plant interactions. Trends 
in Microbiology, Oxford, v. 8, n. 1 p. 298-300, 2000.

LARROSA, R. F. M.; MARCHEZAN, E.; AITA, C.; CORADINI, J. Z. Eficiência da aplicação de nitrogênio no perfilhamento do arroz em três manejos da irrigação. Ciência Rural, Santa Maria, v. 31, n. 4, p. 745-749, 2001.

NEHL, D. B.; ALLEM, S. J.; BROWN, J. F. Deleterious rhizosfere bacteria: an integrating perspective. Applied Soil Ecology, Oxford, v. 5, n. 1, p. 1-20, 1996.

NEVES, A. N. Caracterização in vitro de azospirillum em feijão. Relatório de estágio técnico profissional. Lages: UDESC, 2009. 64 p.

NOVAKOWISKI, J. H.; SANDINI, I. E.; FALBO, M. K.; MORAES, A.; NOVAKOVISKI, J. H.; CHENG, N. C. Efeito Residual da adubação nitrogenada e inoculação de Azospirillum brasiliense na cultura do milho. Semina: Ciências Agrárias, Londrina, v. 32, p. 1687-1698, 2011. Suplemento 1.

PERIN, L.; SILVA, M. F.; FERREIRA, J. S.; CANUTO, E. L.; MEDEIROS, A. F. A.; OLIVARES, F. L.; REIS, V. M. Avaliação da capacidade de estabelecimento endofítico de estirpes de Azospirillum e Herbaspirillum em milho e arroz. Agronomia (UFRRJ), Seropédica, v. 37 , n. 2, p. 47-53, 2003.

PERRIG, D.; BOIERO, M. L.; MASCIARELLI, O. A.; MASCIARELLI, O. A.; PENNA, C.; RUIZ, O. A.; CASSAN, F. D.; LUNA, M. V. Plant-growth-promoting compounds produced by two agronomically important strains of Azospirillum brasilense, and implications for inoculant formulation. Applied Microbiology and Biotechnology, Berlin, v. 75, n. 5, p. 1143-1150, 2007.

REIS, V. M.; PEREIRA, W.; HIPÓLITO, G. S. Métodos de aplicação de bactériasdiazotróficas em cana-soca para fins de determinação de eficiência agronômica. Seropédica: Embrapa, Agrobiologia. 2009. 4 p. (Embrapa:Agrobiologia, Comunicado técnico, 22.
RODRIGUES, E. P. Caracterização fisiológica de estirpes de Azospirillum amazonense e avaliação dos efeitos da inoculação em plantas de arroz inundado (Oryza sativa L.). 2004. Dissertação (Mestrado em Agronomia) - Universidade Federal Rural do Rio de Janeiro, Rio de Janeiro.

ROSSIELlO, R. O. P. Comparação de métodos fotoelétrico e da intersecção na determinação de área, comprimento e raio médio radicular. Pesquisa Agropecuária Brasileira, Brasília, v. 30, n. 5, p. 633-883, 1995.

SABINO, D. C. C. Interação planta-bactéria diazotrófica na cultura do arroz. 2007. Tese (Doutorado em Ciências) - Universidade Federal Rural do Rio de Janeiro, Rio de Janeiro.

SCHENK, M. K.; BARBER, S. A. Phosphate uptake by corn as affected by soil characteristics and root morphology. Soil Science Society of America Journal, Madison, v. 43, n. 5, p. 880-883, 1979.

SOCIEDADE SUL BRASILEIRA DE ARROZ IRRIGADO - SOSBAI. Recomendações técnicas da pesquisa para o sul do Brasil. Porto Alegre: SOSBAI, 2010. 188 p.

TEDESCO, M. J.; GIANELLO, C.; BISSANI, C. A.; BOHNEN, H.; VOLKWEISS, S. J. Análise de solo, planta e outros Materiais. Porto Alegre: Departamento de Solos. Faculdade de Agronomia, 1995. 174 p. (UFRGS, Boletim técnico, 5).

TENNANT, D. A test of a modified line intercept method of estimating root length. Journal of Ecology Applied, London, v. 63, n. 3, p. 995-1001, 1975.

TURNER, F. T.; JUND, M. F. Chlorophyll meter to predict nitrogen topdress requeriment for semidwarf rice. Agronomy Journal, Madison, v. 83, n. 5, p. 926-928, 1991. 